Rachid B. Slimane (Primary Contact)

Gas Technology Institute

1700 South Mount Prospect Road

Des Plaines, IL 60018

rachid.slimane@gastechnology.org

847-768-0606; 847-768-0600 (Fax)

Javad Abbasian

Dept. Chemical \& Environmental Eng.

Illinois Institute of Technology

10 W. $33^{\text {rd }}$ Street

abbasian@iit.edu

312-567-3047; 312-567-8874 (Fax)
Francis S. Lau

Gas Technology Institute

1700 South Mount Prospect Road

Des Plaines, IL 60018

francis.lau@gastechnology.org

847-768-0592; 847-768-0600 (Fax)

Ken H. Ho

Illinois Clean Coal Institute

5776 Coal Drive, Suite 200

Carterville, IL 62918

kenh@icci.org

618-985-3500; 618-985-6166 (Fax)

\title{
New ZnO-Based Regenerable Sulfur Sorbents for Fluid-Bed/Transport Reactor Applications
}

Keywords: Desulfurization, Regeneration, Coalderived fuel gases, Hydrogen sulfide, Sorbent, Zinc titanate, Transport reactor, Fluidized-bed reactor

\section{Introduction}

High-temperature desulfurization of coal-derived fuel gases is an essential process in emerging power generation technologies, such as the Integrated Gasification Combined Cycle (IGCC), aiming to improve both the efficiency and environmental performance of power generation from coal. Hot gas desulfurization may be accomplished by using solid sorbents such as oxides of those metals that form stable sulfides. The effectiveness of a desulfurizing sorbent in treating such gases is related to the predicted equilibrium partial pressure of hydrogen sulfide $\left(\mathrm{H}_{2} \mathrm{~S}\right)$, which will be present in a combination of the reduced form of the sulfide and oxide phases.

The external desulfurization approach consists of passing the hot fuel gases through beds of regenerable sorbents. These sorbents are invariably oxides, which are converted to sulfides during a sulfur loading stage under reducing hot fuel gas conditions and then regenerated by oxidation of the sulfides to oxides and a by-product stream of sulfur dioxide $\left(\mathrm{SO}_{2}\right)$. Regeneration is crucial to the commercial acceptance of external sorbents since they are often made from relatively expensive materials.

For many years, much of the sorbent development work was devoted to sorbents suitable for temperatures greater than $650^{\circ} \mathrm{C}$, since a higher temperature application would offer better overall IGCC process efficiency. However, because of process equipment limitations and other process variables such as fuel gas alkali content, the optimum desulfurization temperature has been recommended in the range of 316 to $538^{\circ} \mathrm{C}\left(600\right.$ to $\left.1000^{\circ} \mathrm{F}\right){ }^{1}$ At these lower temperatures, although the extent of desulfurization improves through more favorable thermodynamic equilibrium, the reactivity of the sorbent is diminished because the kinetic mechanisms for 
sulfidation experience an Arrhenius-type decrease with decreasing temperature. Therefore, a highly reactive sorbent is needed for these lower temperature applications.

For over 25 years, the Gas Technology Institute (GTI) has conducted high temperature gas cleanup R\&D for coal gasification applications. Numerous studies have been conducted at GTI on the potential use of a broad range of materials for the removal of reduced sulfur compounds $\left(\mathrm{H}_{2} \mathrm{~S}\right.$ and $\left.\mathrm{COS}\right)$, hydrogen chloride $(\mathrm{HCl})$ removal, trace metal removal, ammonia $\left(\mathrm{NH}_{3}\right)$ decomposition, and hydrogen cyanide $(\mathrm{HCN})$ hydrolysis. GTI has also been involved in several designs for high temperature gas cleanup systems. ${ }^{2-5}$

During the last decade, hot gas cleanup research at GTI has been focused mainly on the development of regenerable, metal oxide-based sorbents for external desulfurization applications. In more recent years, these sorbents have targeted desulfurization applications in fluidized-beds and/or transport reactors in the moderate temperature range of 343 to $538^{\circ} \mathrm{C}(650$ to $1000^{\circ} \mathrm{F}$ ), which, as mentioned above, has been determined to be optimum for technical viability and efficiency of the integrated gasification combined cycle process. ${ }^{1}$

In projects sponsored by U.S. DOE/NETL, ${ }^{6}$ DCCA/ICCI, ${ }^{7-11}$ and others, ${ }^{12}$ researchers at GTI thoroughly investigated important sorbent synthesis parameters, including preparation technique, chemical composition (main reactive component, additives, binders), induration (calcination) temperature, etc. Consistent with most other R\&D organizations, emphasis was placed on developing sorbents based on $\mathrm{ZnO}$. These were followed by sorbents based on $\mathrm{CuO}, \mathrm{Fe}_{2} \mathrm{O}_{3}$, and $\mathrm{Mn}_{2} \mathrm{O}_{3}$ in this order.

Significant conclusions were drawn from this work. First, no sorbent based on iron oxide $\left(\mathrm{Fe}_{2} \mathrm{O}_{3}\right)$ was found to have sufficient reactivity in the moderate temperature range of interest, i.e., 343 to $538^{\circ} \mathrm{C}\left(650\right.$ to $\left.1000^{\circ} \mathrm{F}\right)$. Second, sorbents based on manganese oxide $\left(\mathrm{Mn}_{2} \mathrm{O}_{3}\right)$ were determined to combine the advantages of high sulfur capacity and high chemical reactivity in the moderate temperature range. One leading manganese-based sorbent (IGTSS-057) achieved an effective sulfur capacity of over $20 \mathrm{~g} \mathrm{~S} / 100 \mathrm{~g}$ sorbent at $450^{\circ} \mathrm{C}$. However, a temperature of at least $750^{\circ} \mathrm{C}$ proved necessary for oxidative regeneration of this Mn-based formulation. Such high temperature could not be readily accommodated by existing desulfurization systems requiring regeneration ignition temperatures of about $538^{\circ} \mathrm{C}\left(1000^{\circ} \mathrm{F}\right)$.

More importantly, research at GTI cast doubt on the feasibility of formulating an effective bulk sorbent based on $\mathrm{ZnO}$ for a demanding commercial desulfurization application, using conventional sorbent preparation techniques, such as co-precipitation or solid oxide mixing followed by granulation or spray drying. These techniques require very high thermal treatment temperatures to impart physical strength, and as a result, they often produce sorbents with low reactivity. It was shown that even when chemical reactivity was compromised significantly (by calcining at temperatures $>1000^{\circ} \mathrm{C}$ ), the minimum attrition resistance requirement for the transport reactor could not be met. To improve chemical reactivity in the moderate temperature range, research at GTI investigated alternative support materials for $\mathrm{ZnO}$; however, non-titania sorbents based on $\mathrm{ZnO}$ showed no improvement over zinc titanate. 
Using "conventional" preparation techniques, research at GTI showed that sorbents based on copper oxide $(\mathrm{CuO})$ had the best combination of high attrition resistance, excellent $\mathrm{H}_{2} \mathrm{~S}$ removal efficiency, and high effective capacity for sulfur absorption in the moderate temperature range. ${ }^{13}$ In addition, only $\mathrm{CuO}$-based sorbents met the stringent combination of high chemical reactivity and high resistance to attrition that is required by the transport reactor application. ${ }^{14}$ Unfortunately, despite the excellent attributes of the $\mathrm{Cu}$-based sorbents, the leading formulations could not be evaluated according to DOE/NETL's Test Protocol for qualification of candidate sorbents for demonstration. It proved very difficult to sustain good and uniform fluidization with $\mathrm{Cu}$-based sorbents in the reducing fuel gas environment during the desulfurization step in a fluidized-bed reactor. Very strong attractive inter-particle forces appeared to develop, resulting in sluggishness and ultimately complete defluidization of the sorbent bed. ${ }^{15,16}$

Given the above results, it became evident that for desulfurization applications relying on fluidbed and/or transport reactor technology at moderate temperature, "conventional" sorbent preparation techniques, such as co-precipitation or solid oxide mixing followed by granulation or spray drying, may not be suitable for preparing sorbents with attrition resistance, chemical reactivity, and fluidization properties that meet the stringent requirements of these reactors. An alternative sorbent preparation approach was deemed necessary. In addition, because sorbents based on $\mathrm{ZnO}$ are best suited for desulfurization, particularly in the moderate temperature range of interest, significant efforts were devoted to developing a suitable approach for the preparation of effective Zn-based sorbents.

\section{Objective}

The overall objective of the ongoing sorbent development work at GTI is the advancement to the demonstration stage of a promising $\mathrm{ZnO}-\mathrm{TiO}_{2}$ sulfur sorbent that has been developed under DCCA/ICCI and DOE/NETL sponsorship. This regenerable sorbent has been shown to possess an exceptional combination of excellent chemical reactivity, high effective capacity for sulfur absorption, high resistance to attrition, and regenerability at temperatures lower than required by typical zinc titanates.

\section{Approach}

To overcome the limitations of "conventional" sorbent preparation methods, GTI has developed a proprietary technique based on sol-gel processing of inorganic and organic precursors. A patent application has been filed in February 2002. ${ }^{17}$ Sol-gel processing typically consists of preparation of a stable sol, gelation of the sol, and removal of the solvent. Unfired gels have enormous surface area (300-1000 $\left.\mathrm{m}^{2} / \mathrm{g}\right)$, which serves as a driving force to bring about sintering at exceptionally low temperatures $\left(450^{\circ} \mathrm{C}\right.$ as opposed to temperatures as high as $1100^{\circ} \mathrm{C}$ for "conventional" sorbent preparation techniques). The key to this approach is that, because it is not necessary to calcine these sorbents at very high temperatures, the desirable characteristics of unfired gels are retained following calcination at the moderate temperature of $450^{\circ} \mathrm{C}$. These characteristics were exploited to synthesize regenerable $\mathrm{ZnO}-\mathrm{TiO}_{2}$ (i.e., zinc titanate) sorbents with the highly desirable combination of excellent micro-structural control (high surface areas and small pore sizes) and very high attrition resistance that well exceeds the stringent requirement of the transport reactor desulfurization application. 
A novel class of regenerable Zn-based sorbent formulations has been prepared using the developed techniques. The original procedure relied on the preparation of a stable sol of the support material (i.e., $\mathrm{TiO}_{2}$ or alternative, if desired). Under DCCA/ICCI sponsorship, this new sorbent synthesis approach was simplified considerably to minimize the number of steps involved, thereby reducing processing times and sorbent cost. In addition, a suitable commercial manufacturer (Chemat Technology, Inc. in Los Angeles, California) was identified for the preparation of the leading formulation, using the simplified sol-gel procedure. This led to further modifications of the simplified procedure to adapt it to commercial practice. These modifications included substantial reductions in the reagents used during sorbent preparation. Several leading zinc titanate sorbent formulations have so far been prepared successfully by Chemat Technology, including two formulations in an ongoing project under DCCA/ICCI and DOE/NETL sponsorship. ${ }^{18}$

Granules from each prepared sorbent were then produced in the desired size range of 45-180 $\mu \mathrm{m}$ for testing in a high-pressure thermogravimetric analyzer (HPTGA), ambient-pressure packed/fluidized-bed reactors, and a high-pressure fluidized-bed reactor. Relevant characteristics of fresh as well as reacted sorbent samples were determined, including composition by wet chemical analysis, physical properties (particle and skeletal densities, pore volume, total pore surface area, and median pore diameter) by mercury porosimetry and BET surface area, and attrition resistance according to the ASTM D5757-95 method. The granular sorbents were evaluated for their rate of sulfur pick-up, efficiency for $\mathrm{H}_{2} \mathrm{~S}$ removal, effective capacity for sulfur absorption, and regenerability in an ambient-pressure packed-bed reactor. Desulfurization temperatures in the range of 343 to $538^{\circ} \mathrm{C}\left(650\right.$ to $\left.1000^{\circ} \mathrm{F}\right)$ were investigated using simulated fuel gas mixtures ranging from simple $\mathrm{H}_{2} \mathrm{~S}-\mathrm{H}_{2}-\mathrm{H}_{2} \mathrm{O}-\mathrm{N}_{2}$ to compositions simulating the KRW commercial fuel gas composition $\left(15 \% \mathrm{H}, 24 \% \mathrm{CO}, 6 \% \mathrm{CO}_{2}, 6 \% \mathrm{H}_{2} \mathrm{O}, 0.5-2 \% \mathrm{H}_{2} \mathrm{~S}\right.$, and 47$48.5 \% \mathrm{~N}_{2}$ ).

\section{Project Description}

A sorbent synthesis technique has been developed at GTI, based on solgel processing, for the preparation of $\mathrm{ZnO}$-based regenerable sulfur sorbents with unique properties that could not be achieved by "conventional" sorbent preparation methods. This technique eliminates the need for excessively high thermal treatment temperatures to impart the required physical strength to sorbents and has made possible the achievement of the challenging combination of high reactivity (desirable pore size distribution and high surface area), high attrition resistance, and regenerability at lower temperature.

Under DOE/NETL sponsorship, ${ }^{6}$ early versions of sorbents prepared with this new technique demonstrated attrition indices that are well below the stringent requirement of the transport reactor of $\approx 4 \%$, and effective capacities for sulfur absorption exceeding $8 \mathrm{~g} \mathrm{~S} / 100 \mathrm{~g}$ of sorbent. With support from DCCA/ICCI, ${ }^{11}$ efforts continued to further develop this new sorbent synthesis approach. Various issues have been addressed, including (i) simplification of the sol gel-based sorbent preparation procedure to minimize the number of steps involved, thereby reducing processing times and sorbent cost; (ii) identification of a suitable commercial manufacturer for the preparation of the leading formulation, using the simplified solgel procedure; and (iii) further modifications of the simplified procedure to adapt it to commercial practice. Bulk 
quantities of the leading sorbent have been prepared commercially and this formulation evaluated in a bench-scale high-pressure fluidized-bed reactor.

In an ongoing DCCA/ICCI-funded project, ${ }^{18}$ the composition of the leading sorbent formulation has been optimized with respect to its $\mathrm{ZnO}$ content. This new sorbent formulation is being used to develop further understanding of optimum sorbent regeneration requirements to maintain desirable performance over many cycles. Validation of sorbent performance at DOE/NETL facilities will also be undertaken in a CRADA program. A data package will be developed to demonstrate the capability of GTI's leading zinc titanate sorbent to meet the requirements of anticipated demonstration applications.

Following successful completion of the ongoing project, GTI plans to demonstrate its leading sorbent in a gasifier pilot-plant facility that GTI is currently constructing. GTI will seek funding from DOE/NETL to build a suitable bubbling fluidized-bed reactor that can be integrated into the pilot plant facility, and used to evaluate the zinc titanate sorbent using actual coal gases at realistic process temperatures and pressures.

\section{Results}

To illustrate the exceptional characteristics of this new class of $\mathrm{ZnO}-\mathrm{TiO}_{2}$ sorbents, two formulations will be used. The first formulation, IGTSS-354, was developed in the DOE/NETLfunded program ${ }^{6}$ based on an early version of the sorbent preparation procedure. IGTSS-354 was prepared at GTI with a nominal $\mathrm{ZnO}$ content of about $30 \%$ by weight. The second formulation, designated as IGTSS-362C, was developed under DCCA/ICCI sponsorship ${ }^{11}$ and was manufactured commercially by Chemat Technology with a nominal $\mathrm{ZnO}$ content of about $40 \mathrm{wt} \%$. The chemical analyses of these two new formulations as well as those of a "conventional" UCI-4169 zinc titanate sorbent are reported in Table 1. It should be noted that the $\mathrm{ZnO}$ content of the IGTSS-354 and IGTSS-362C sorbents are about half that of the baseline UCI-41C9 zinc titanate sorbent.

The results of physical characterization of the two selected sol-gel-derived sorbents (i.e., IGTSS354 and IGTSS-362C) as well as those of the UCI-4169 prepared using "conventional" techniques are summarized in Table 2. Comparison of these results indicates that although both types of sorbents have similar densities and porosities, the mercury pore surface areas of the solgel derived sorbents are one to two orders of magnitude higher than those prepared by other techniques. The high surface areas of the sol-gel-derived sorbents should be attributed to their significantly smaller pore diameters. This desirable combination of high porosity, high surface area, and small pore diameters resulted in higher chemical reactivity and much higher attrition resistance for these sorbents compared to sorbents prepared using "conventional" techniques, as substantiated below.

\section{Comparison of Attrition Resistance}

Figure 1 reports the results from attrition tests carried out on the two selected sorbents (i.e., IGTSS-354 and IGTSS-362C) that were prepared using the solgel approach. These results are also compared against those obtained with the commercial UCI-4169 zinc titanate sorbent that was prepared using "conventional" techniques, as indicated earlier, and a baseline FCC material. The results reported in Figure 1 are in terms of the attrition jet index (AJI), as defined by the 
ASTM D5757-95 procedure, which corresponds to the 5-hour loss. As shown in this figure, the new zinc titanate sorbents achieved attrition losses that are about half that of the FCC material and about $\underline{1 / 10}$ that of the "conventional" zinc-based sorbent.

Figure 2 compares the attrition resistance performance of IGTSS-354 and IGTSS-362C sorbents with those of the UCI-4169 zinc titanate sorbent and the FCC baseline material. Attrition resistance in this figure is reported in accordance with DOE/NETL's definition of $\left(5^{\text {th }} \mathrm{hr}-1^{\text {st }}\right.$ $\mathrm{hr}) / 4$, i.e., the average per hour loss due to attrition with the first hour loss not taken into consideration to eliminate any particle size effects on attrition. As shown, IGTSS-354 and IGTSS-362C demonstrated significantly lower attrition losses than the "conventional" zinc titanate sorbent, and greatly exceeded the stringent requirement of the transport reactor at Piñon Pine, as indicated by the solid line on Figure 2.

\section{Chemical Reactivity and Regenerability}

Desulfurization (sulfidation) breakthrough curves obtained from evaluation of the "conventional" UCI-4169 zinc titanate sorbent and the two selected sol-gel-derived sorbents (IGTSS-354 and IGTSS-362C) in a packed-bed reactor at $450^{\circ} \mathrm{C}$ are compared in Figure 3. All three sorbents were evaluated under the same operating conditions of sulfidation gas composition, sorbent bed configuration, space velocity, inlet $\mathrm{H}_{2} \mathrm{~S}$ concentration, etc. As shown, the UCI-4169 sorbent achie ved an effective capacity of only about $3.5 \mathrm{~g} \mathrm{~S} / 100 \mathrm{~g}$ sorbent, which represents about $16 \%$ of its theoretical sulfur capacity (refer to Table 1). GTI's zinc titanate sorbents, on the other hand, achieved effective capacities approximating 7.5 and $11.4 \mathrm{~g} \mathrm{~S} / 100 \mathrm{~g}$ sorbent for the IGTSS-354 and IGTSS-362C formulations, respectively. These values represent about $79 \%$ and $84 \%$ of the theoretical sulfur capacity of each sorbent formulation.

Sorbent regenerability tests carried out on the sol-gel-based zinc titanates repeatedly showed that these sorbents could be regenerated fully at $593^{\circ} \mathrm{C}\left(1100^{\circ} \mathrm{F}\right)$ with $\underline{\text { dry }}$ oxidative gases. At the lower temperature of $538^{\circ} \mathrm{C}\left(1000^{\circ} \mathrm{F}\right)$, extensive testing showed that these sorbents could also be regenerated completely provided the regeneration gas contains steam, i.e., "wet" gas. Steam at the $10 \%$ level was sufficient to ensure complete sorbent regeneration. Figure 4 shows regeneration breakthrough curves for the IGTSS-354 sorbent at $593^{\circ} \mathrm{C}$ with dry and "wet" regeneration feed gases. As shown, in both cases, the $\mathrm{SO}_{2}$ content of the regeneration product gas closely approaches the theoretical value (based on regeneration reaction stoichiometry and $\mathrm{O}_{2}$ content of feed gas) with a sharp breakthrough when the sorbent is fully regenerated. Therefore, the IGTSS-354 sorbent can be successfully regenerated at $593^{\circ} \mathrm{C}$ with or without steam in the feed gas.

The same is true for the commercially produced IGTSS-362C sorbent, as shown in Figure 5. In addition to regeneration breakthrough curves, Figure 5 shows the regeneration temperature profile, measured by a thermocouple placed in the middle of the sorbent bed. As indicated, because of the low oxygen content $\left(3\right.$ to $5 \mathrm{vol} \% \mathrm{O}_{2}$ ) used in these tests, the temperature was purposely controlled to $<625^{\circ} \mathrm{C}$. Other multi-cycle tests showed that sorbent effectiveness could be retained during a cyclic sulfidation/regeneration process, provided the sorbent is not exposed to temperatures $>\approx 675^{\circ} \mathrm{C}\left(1250^{\circ} \mathrm{F}\right)$. 
To assess the improved regenerability of this new class of Zn-based sorbents, developed based on a simplified sol gel procedure, over that of a typical "conventional" Zn-based sorbent, the UCI-4169 zinc titanate sorbent was sulfided at $550^{\circ} \mathrm{C}$ (to achieve a sulfur loading similar to that of the IGTSS-362C at $450^{\circ} \mathrm{C}$ ) and then regenerated under the same conditions as the IGTSS362C sorbent (Figure 5). As shown on Figure 6, while it took only about 2 hours to fully regenerate the IGTSS-362C sorbent, the UCI-4169 zinc titanate sorbent, which was loaded (sulfided) $\mathfrak{b}$ the same extent, took an entire 14 hours, and even after that period, the $\mathrm{SO}_{2}$ concentration in the regeneration product gas was still being measured at about 0.2 vol\% (i.e., 2000 ppmv $\mathrm{SO}_{2}$ ). Also, as seen in Figure 6, regeneration of the "conventional" UCI-4169 sorbent is quite sluggish, a clear indication of significant sulfate formation. It is well established in the literature that zinc titanate cannot be efficiently regenerated at temperatures below about $625^{\circ} \mathrm{C} .{ }^{19}$ Therefore, the zinc titanates prepared using GTI's proprietary sorbent preparation technique have inherently lower regeneration temperatures than conventional zinc titanate sorbents.

\section{Application}

One of the main obstacles in the commercialization of high-temperature desulfurization systems for IGCC power generation processes is the development of regenerable sulfur sorbents with suitable physical and chemical characteristics. These characteristics greatly depend on the type of reactor used for desulfurization/regeneration, which can have a fixed-bed, a moving-bed, a transport reactor, or a bubbling fluidized-bed. In recent years, the use of transport reactors for hot fuel gas desulfurization has been promoted. In addition, because of the stringent limits on emissions, hot gas cleanup is likely to be conducted in the moderate temperature range of 343 to $538^{\circ} \mathrm{C}\left(650\right.$ to $\left.1000^{\circ} \mathrm{F}\right)$. Operating at moderate temperature in fluid-bed and/or transport reactors places tough requirements on the sorbents that must be used. As substantiated above, the new zinc titanate sorbents developed at GTI are uniquely qualified for such operating conditions.

In addition to meeting the requirements of IGCC processes for power generation, there is currently interest in extending the hot gas cleanup capabilities so that the cleaned fuel gas becomes suitable for other applications, such as fuel cells, co-production of power with chemical products or transportation fuels. These applications will require the removal of several contaminants (including reduced sulfur compounds) to the ppbv range to satisfy downstream syngas catalyst and membrane separation requirements. Because of their high surface area and high chemical reactivity at moderate temperatures, GTI's zinc titanate sorbents are potentially suitable for these emerging, more stringent desulfurization applications.

\section{Future Activities}

In the ongoing project, ${ }^{18}$ with continuing funding from DCCA/ICCI and US DOE/NETL (in the form of a CRADA), the composition of the leading sorbent formulation (IGTSS-362C) has been optimized with respect to its $\mathrm{ZnO}$ content. The new leading zinc titanate sorbent, designated as ZT050-1, has been produced successfully by Chemat, and is currently undergoing evaluation at GTI to develop an effective regeneration strategy that prevents temperature excursions beyond $675^{\circ} \mathrm{C}\left(1250^{\circ} \mathrm{F}\right)$ so that the sorbent retains its performance during cycling. Desulfurization performance of the ZT050-1 zinc titanate sorbent is depicted in Figure 7. Also in this program, the performance of GTI's zinc titanate sorbent will be validated at a suitable hot gas cleanup facility at NETL. A test plan is being developed so that a data package is developed in the 
CRADA program, demonstrating the capability of GTI's zinc titanate sorbent to meet the requirements of anticipated demonstration applications. Sorbent performance validation at DOE/NETL will use a recirculating transport riser reactor in NETL's Fuel Processing Research Facility (Figure 8). Should this facility not be operational on time for this planned work, an alternative single-pass transport riser reactor will be used (Figure 9).

Following successful completion of the ongoing project, GTI plans to demonstrate its leading zinc titanate sorbent in a state-of-the-art gasifier facility (Figure 10) that is currently being constructed at GTI. GTI will seek funding from DOE/NETL to build a suitable bubbling fluidized-bed reactor that can be integrated into the pilot plant facility, and used to evaluate the zinc titanate sorbent using actual coal gases at realistic process temperatures and pressures.

\section{Acknowledgment}

Financial support for the studies mentioned in this paper has been provided by DOE/NETL and the Illinois Department of Commerce and Community Affairs through the Illinois Clean Coal Institute. Any opinions, findings, conclusions or recommendations expressed herein are those of the authors and do not necessarily reflect the views of the sponsors.

\section{References}

1. NOVEM. 1991. "System Study High Temperature Gas Cleaning at IGCC Systems." Netherlands Agency for Energy and the Environment.

2. "Hot Gas Cleanup for Coal Conversion Processes", G.L. Anderson. Paper presented at the Symposium on Advances in Coal Utilization Technology, Lousiville, KY, May 14-18, 1979

3. "Predictions on the Disposition of Select Trace Elements in Coal Gasification Processes", G.L. Anderson, A.H. Hill and D.K. Fleming. Paper presented at the Environmental Aspects of Fuel Conversion Technology Symposium, Hollywood, FL, April 17-20, 1979.

4. "Purification of Fuel Gases," G.L. Anderson, H.A. Borders, and M.R. Aquino. U.S. Patent 4,374,105 issued February 15, 1983.

5. "Desulfurization of $\mathrm{H}_{2} \mathrm{~S}$ Containing Gas Streams with Production of Elemental Sulfur," G.L. Anderson, H.A. Borders, and F.O. Berry. U.S. Patent 4,363,790 issued December 14, 1982.

6. "Advanced Sorbent Development Program," DOE Contract No. DE-AC21-94MC31089, GTI Project No. 65111, Sept. 30, 1994 - March 31, 2000

7. "Development of Regenerable Copper-Based Sorbents for Hot Gas Cleanup," ICCI Project No. 95-1/2.2A-5M, GTI Project No. 40364, Sept. 1, 1995 through Aug. 31, 1996

8. “Copper-Based Sorbents for Hot Gas Desulfurization Systems," ICCI Project No. 961/2.2A-3, GTI Project No. 40374, Sept. 1, 1996 through Aug. 31, 1997

9. "Highly Attrition Resistant Sorbents for Desulfurization of Hot Coal Gases," ICCI Project No. 97-1/5.2A-4, GTI Project No. 40390, Sept. 1, 1997 through Feb. 28, 1998 
10. "Development of Novel Sorbents for Hot Gas Desulfurization in IGCC," ICCI Project No. 97-1/5.2A-2, GTI Project No. 40391, Sept. 1, 1997 through Aug. 31, 1998

11. "Movement of IGT's Hot Gas Cleanup Sorbent Towards the IGCC Demonstration Stage, " ICCI Project No. 99-1/1.3A-1, GTI Project No. 40430, Nov. 1, 1999 through Oct. 31, 2000

12. "Desulfurization of High Moisture Content Fuel-Gases Derived from Low-Rank Coals," S. Hodges, B. Anderson, J. Abbasian, and R. B. Slimane, Proceedings of the $4^{\text {th }}$ International Symposium \& Exhibition on Gas Cleaning at High Temperatures, 22-24 Sept. 1999, University of Karlsruhe, Karlsruhe, Germany, pp. 612-623.

13. "Regenerable Mixed Metal Oxide Sorbents for Coal Gas Desulfurization at Moderate Temperatures," R.B. Slimane and J. Abbasian. Advances in Environmental Research, Vol. $\underline{4}$, Issue 2, Aug. 2000, pp.147-162.

14. "Copper-Based Sorbents for Coal Gas Desulfurization at Moderate Temperatures," R.B. Slimane and J. Abbasian. Ind. Eng. Chem. Res., Vol. 39, No. 5, 2000, 1338-1344.

15. "Movement of IGT's Hot Gas Cleanup Sorbent Towards the IGCC Demonstration Stage," Slimane, R. B., Abbasian, J., Williams, B. E., and Rabiei, S., Final Technical Report to the Illinois Clean Coal Institute, November 2000.

16. "Validation and Deployment of GTI's Leading Zinc Titanate Sulfur Sorbent," Slimane, R.B., et al., Proceedings of the $27^{\text {th }}$ International Technical Conference on Coal Utilization \& Fuel Systems, March 4-7, 2002, Clearwater, FL

17. "New ZnO-Based Regenerable Sulfur Sorbents for Fluid-Bed/Transport Reactor Applications," R.B. Slimane, J. Abbasian, and B.E. Williams, Patent Application, Filing Date: Feb. 28, 2002; Serial No.: 10/086,168 (GTI Ref.\#01-1480).

18. "Validation and Deployment of GTI's Leading Zinc Titanate Sulfur Sorbent," ICCI Project No. 01-1/2.3A-1, GTI Project No. 40473, Nov. 1, 2001 through Oct. 31, 2002.

19. Jothimurugesan, K. and Gangwal, .S K. "Regeneration of Zinc Titanate $\mathrm{H}_{2} \mathrm{~S}$ Sorbents," Ind. Eng. Chem. Res. 1998, 37, 1929-1933.

\section{Figures and Tables}




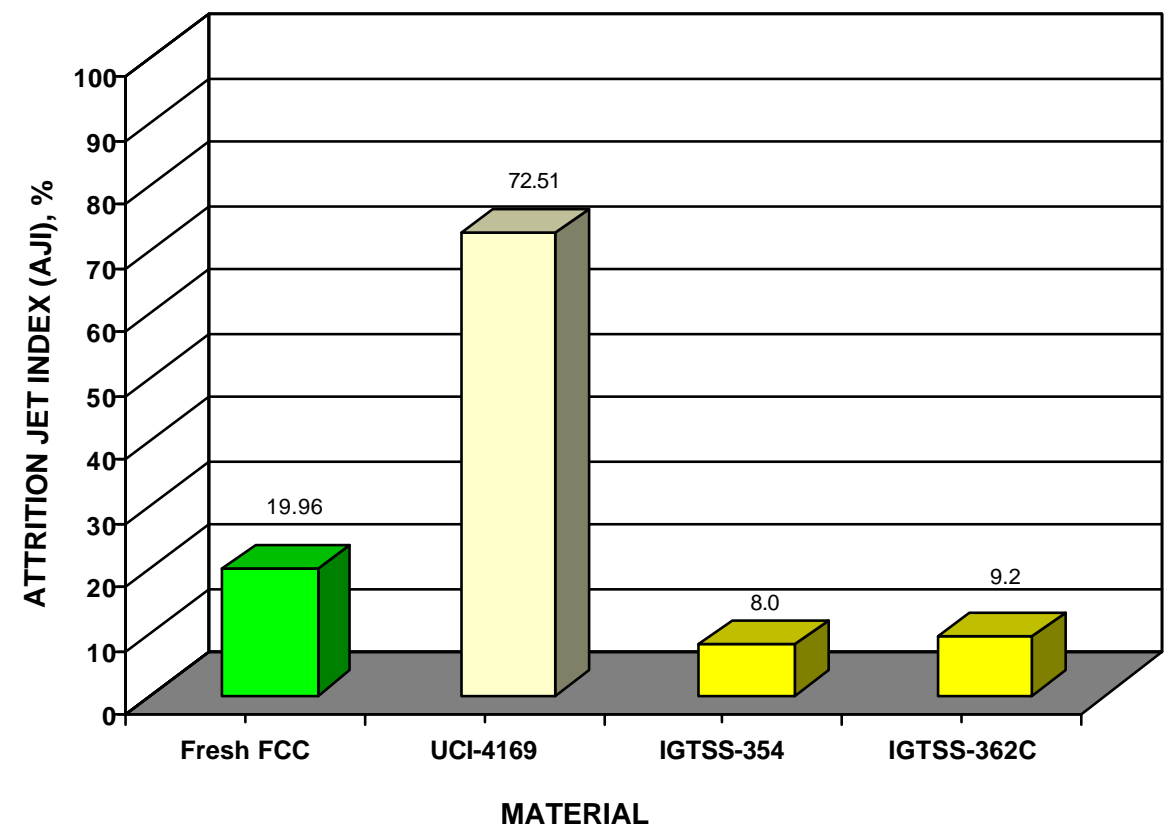

Figure 1. Attrition Resistance of New and "Conventional" ZnO-Based Sorbents

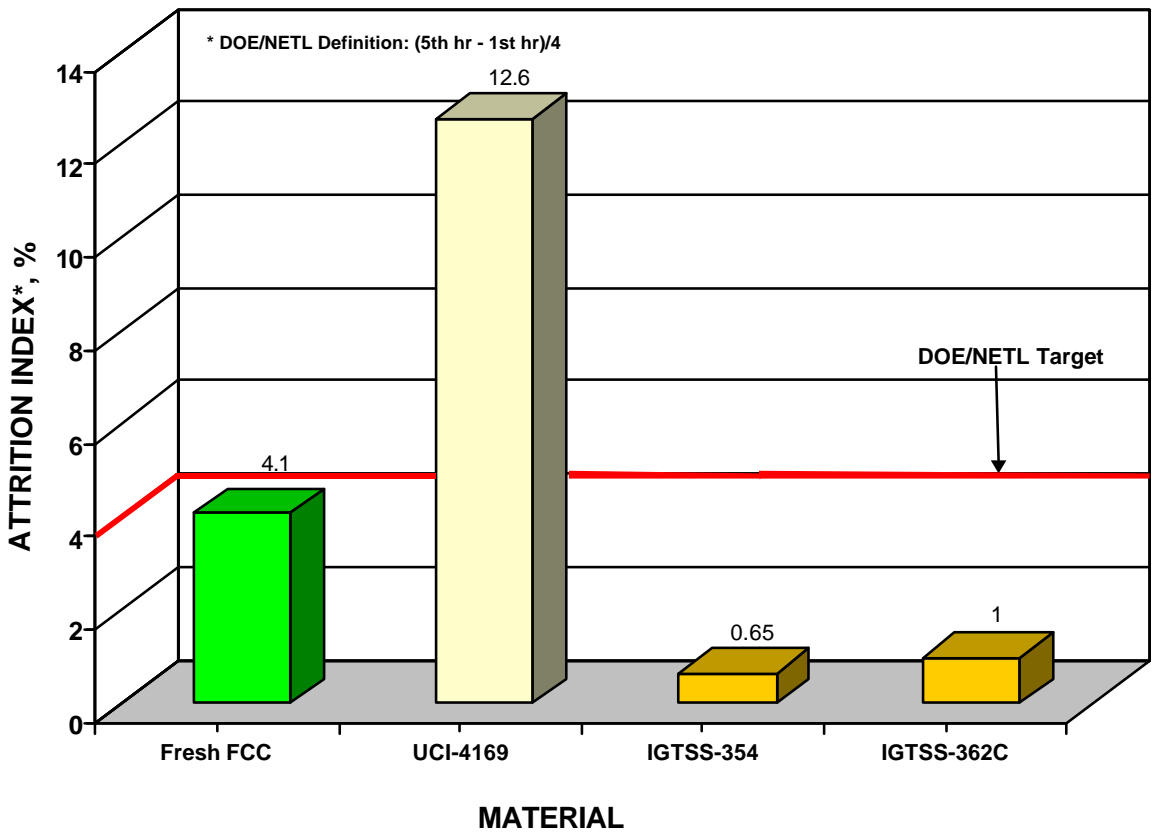

Figure 2. Attrition Resistance of Selected Sorbents 


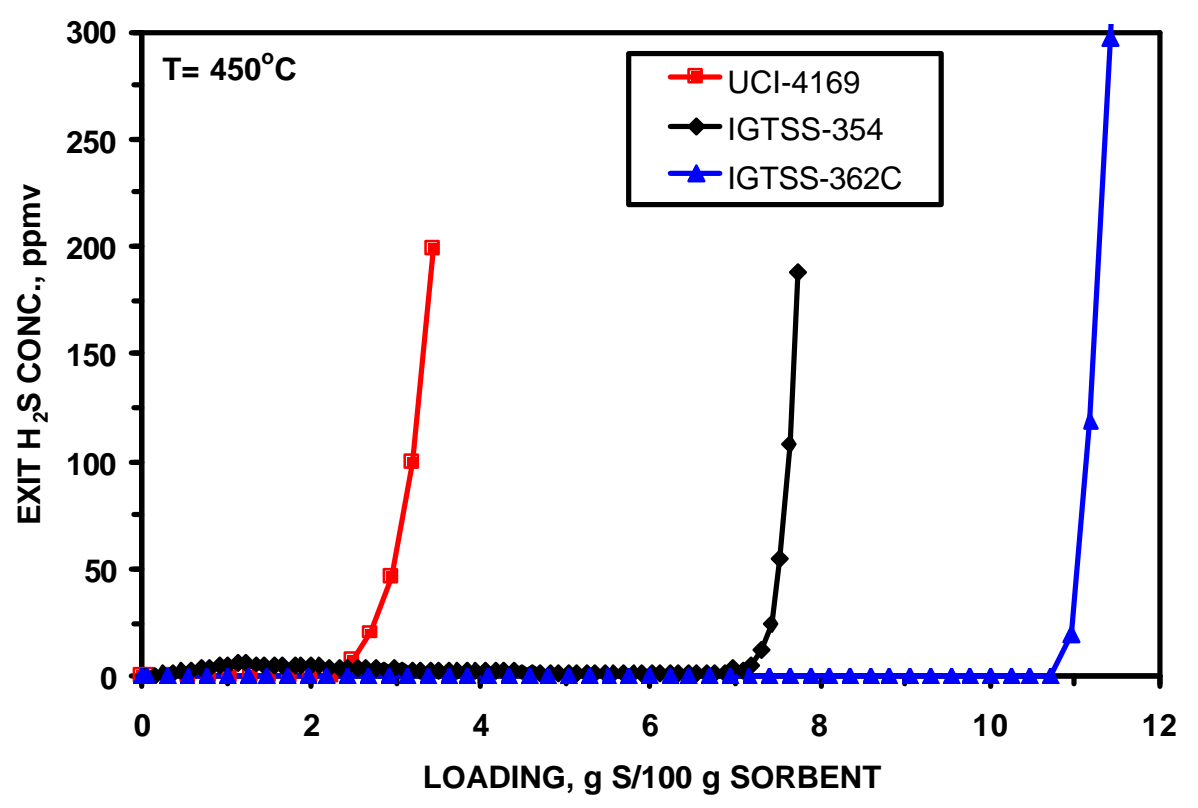

Figure 3. Comparison of Sorbent Desulfurization Performance

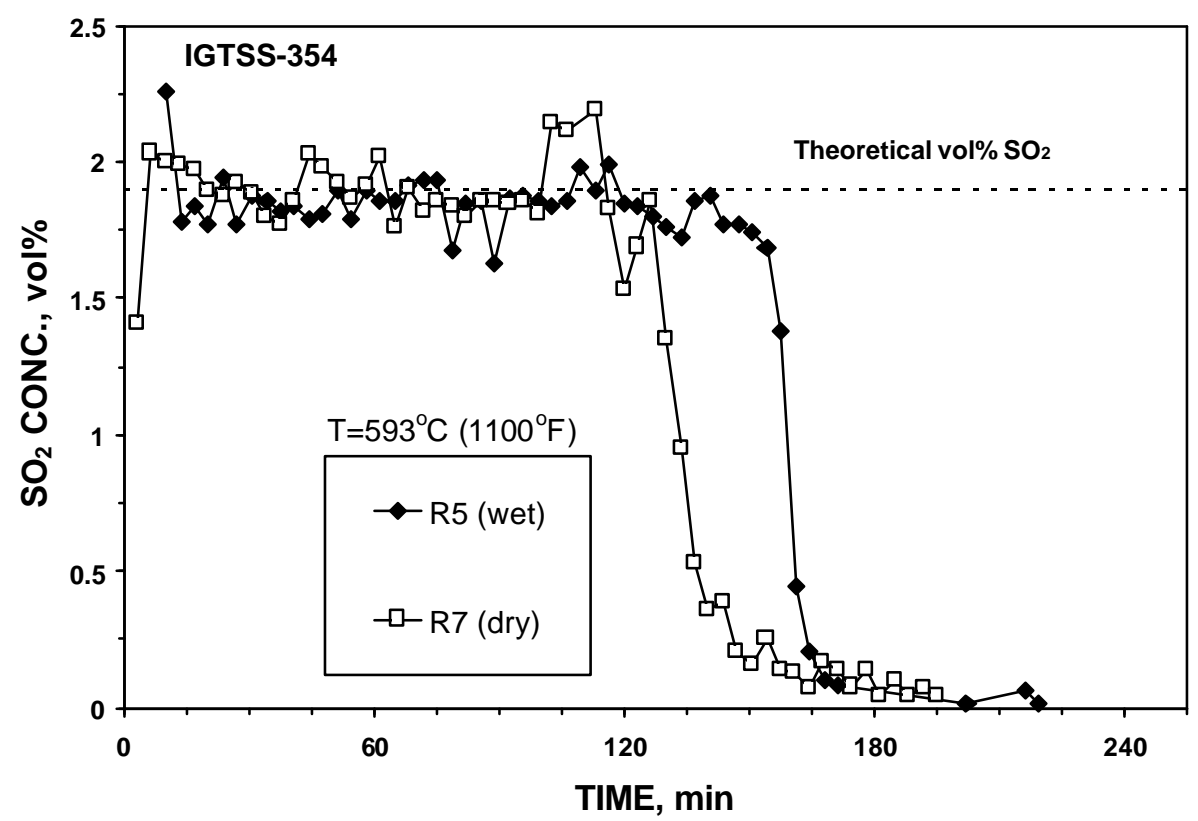

Figure 4. Regenerability of IGTSS-354 Sorbent at $593^{\circ} \mathrm{C}\left(1100^{\circ} \mathrm{F}\right)$ 


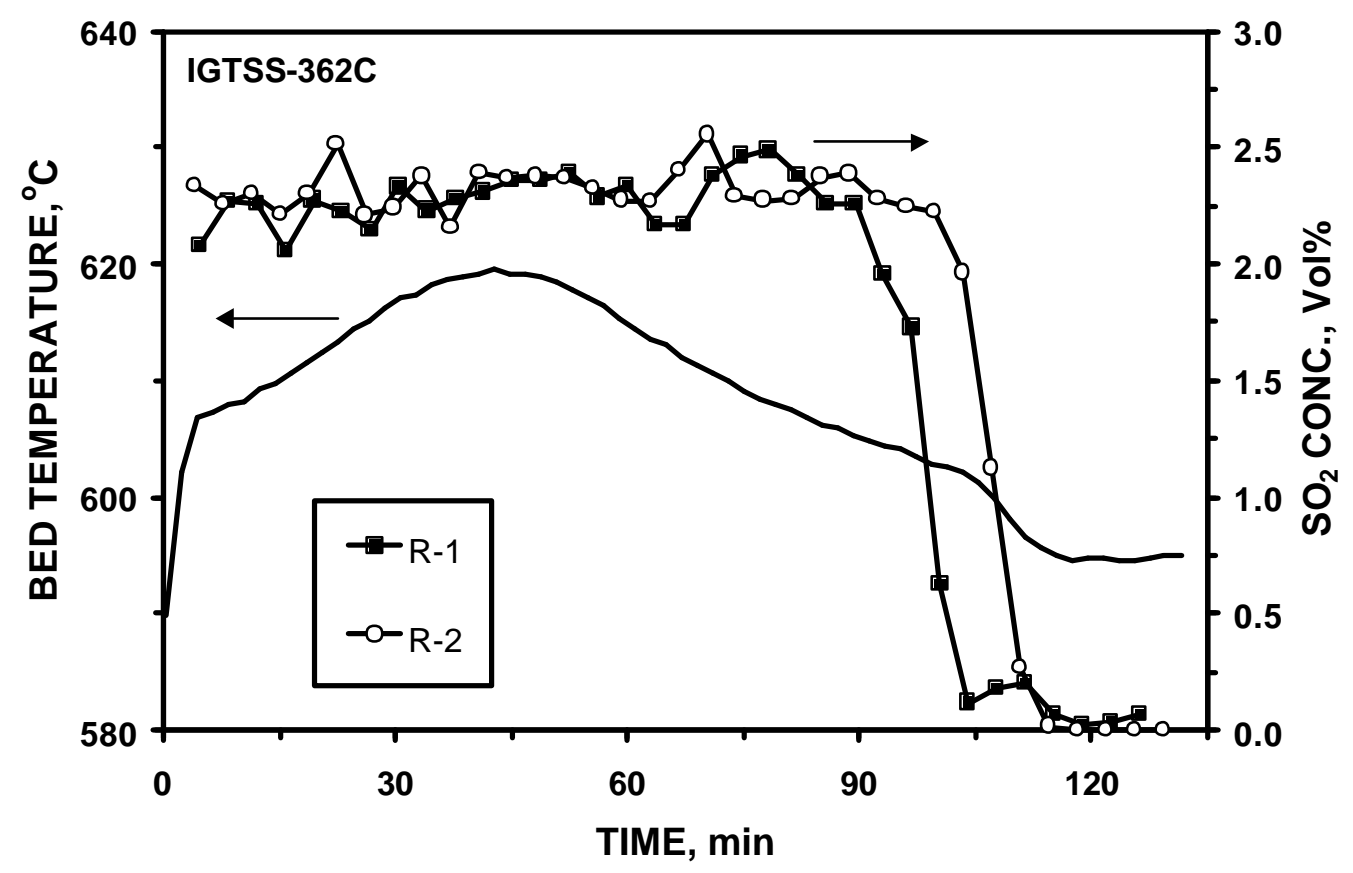

Figure 5. Regenerability of IGTSS-362C Sorbent at $593^{\circ} \mathrm{C}\left(1100^{\circ} \mathrm{F}\right)$

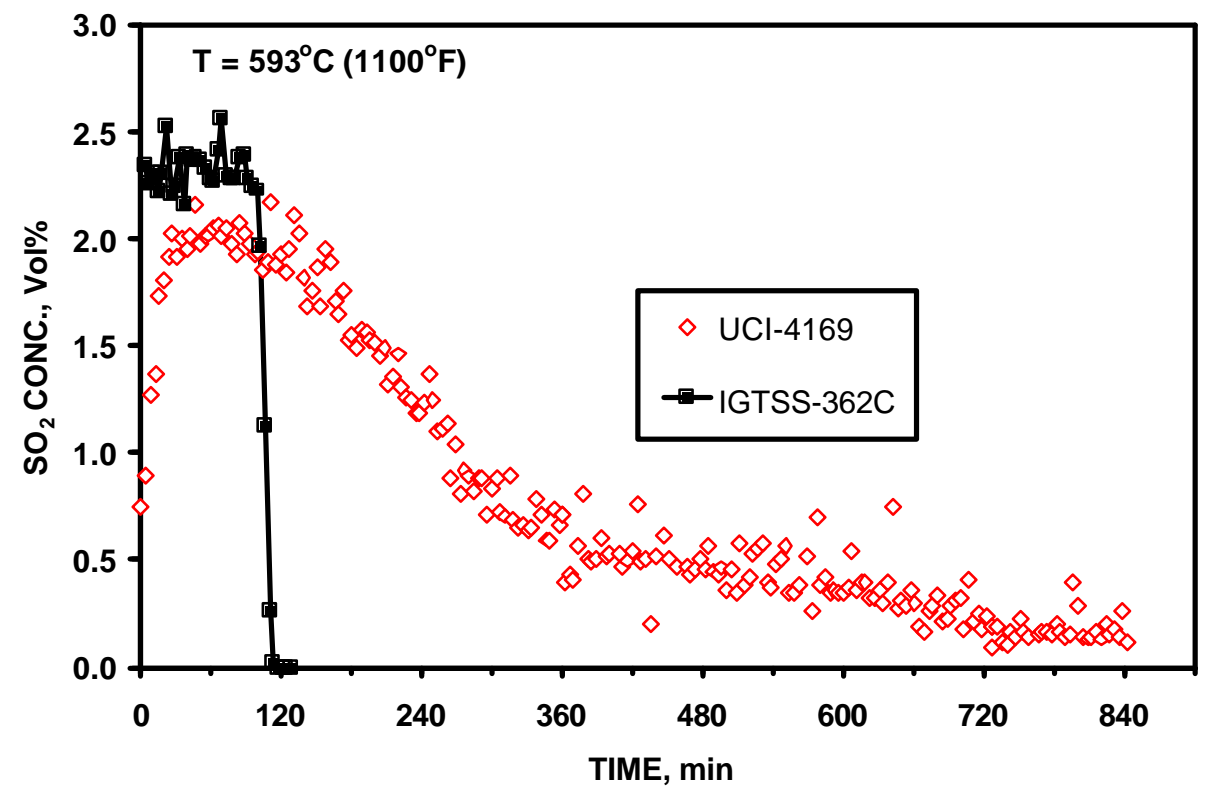

Figure 6. Comparison of Regenerability of New (GTI's) and "Conventional" Zinc Titanate Sorbents 


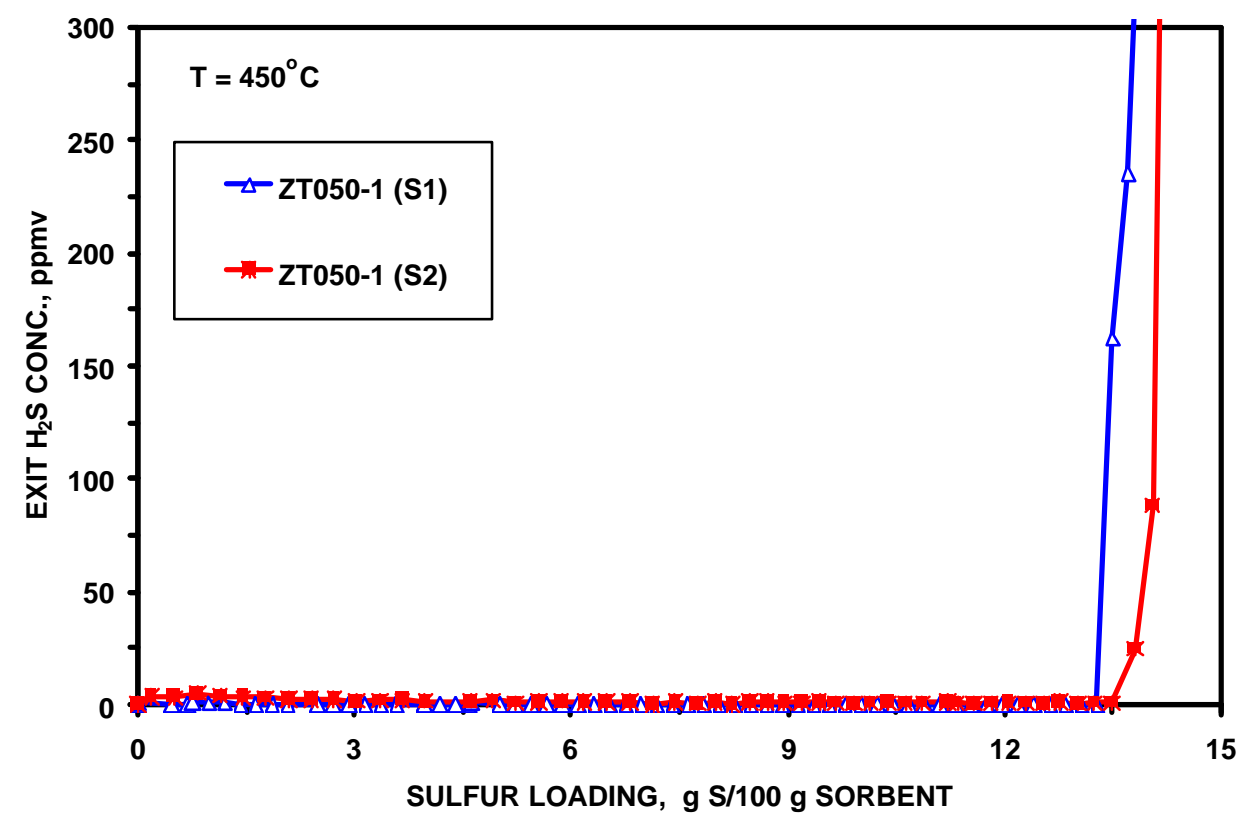

Figure 7. Desulfurization Performance of GTI's ZT050-1 Zinc Titanate Sorbent

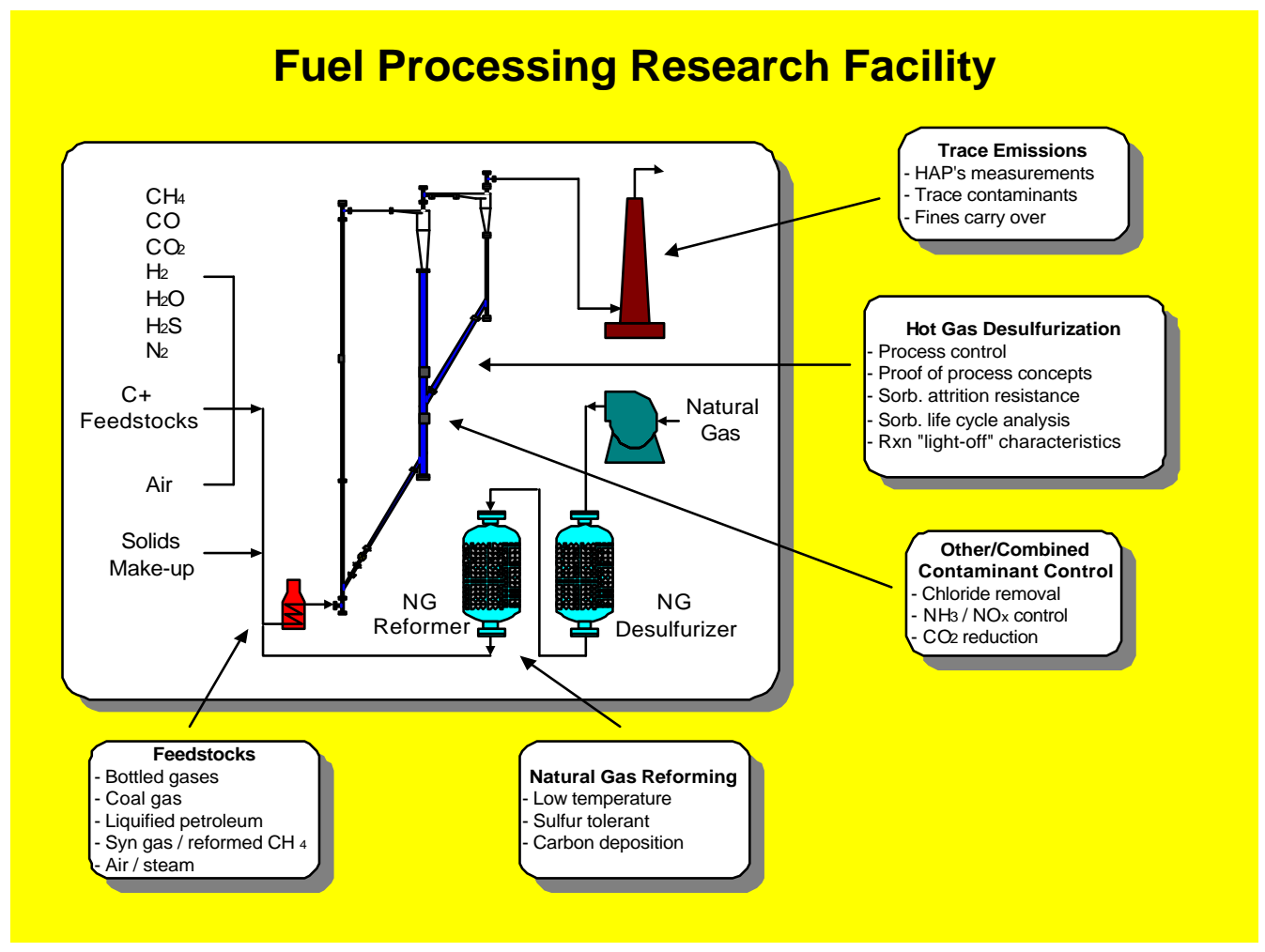

Figure 8. DOE/NETL's Fuel Processing Research Facility 


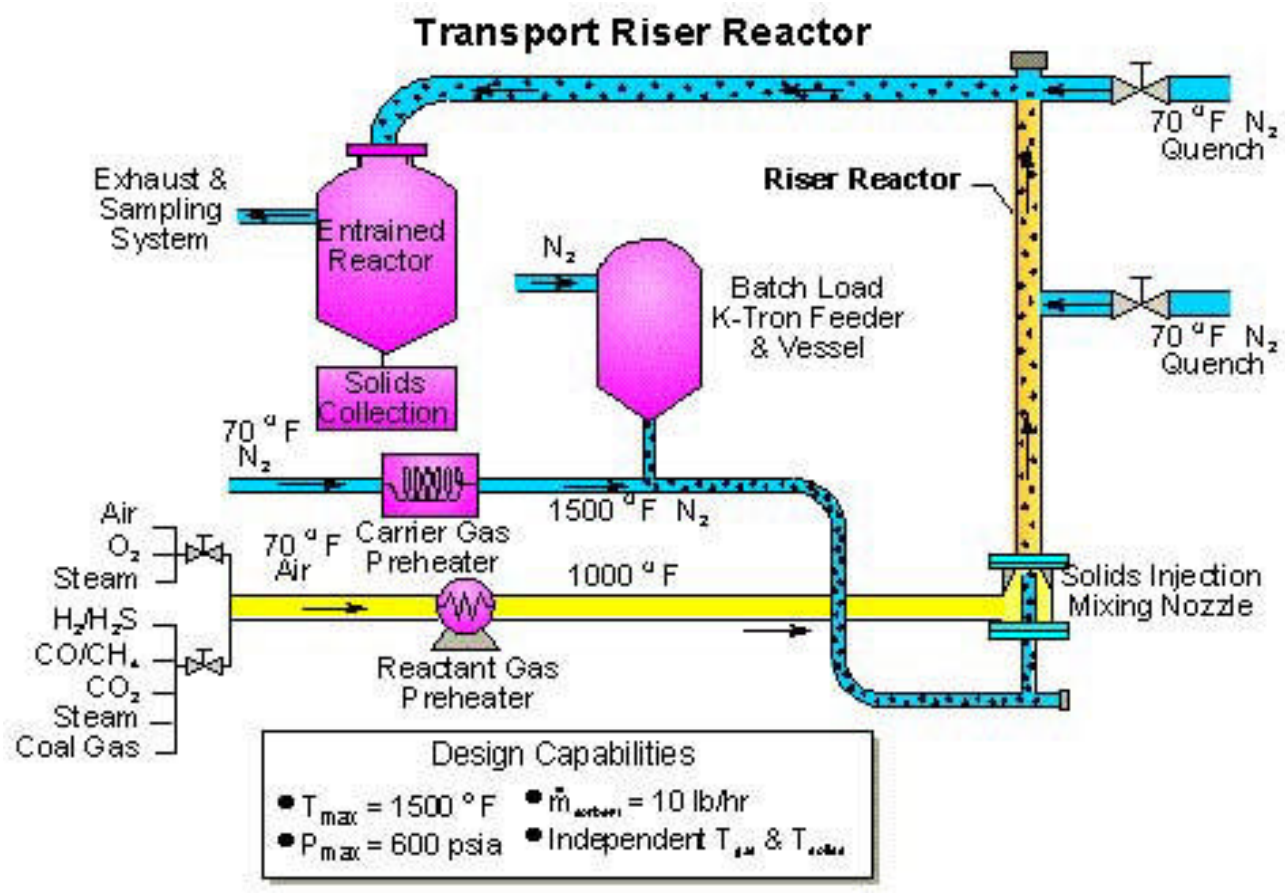

Figure 9. DOE/NETL's Transport Riser Reactor

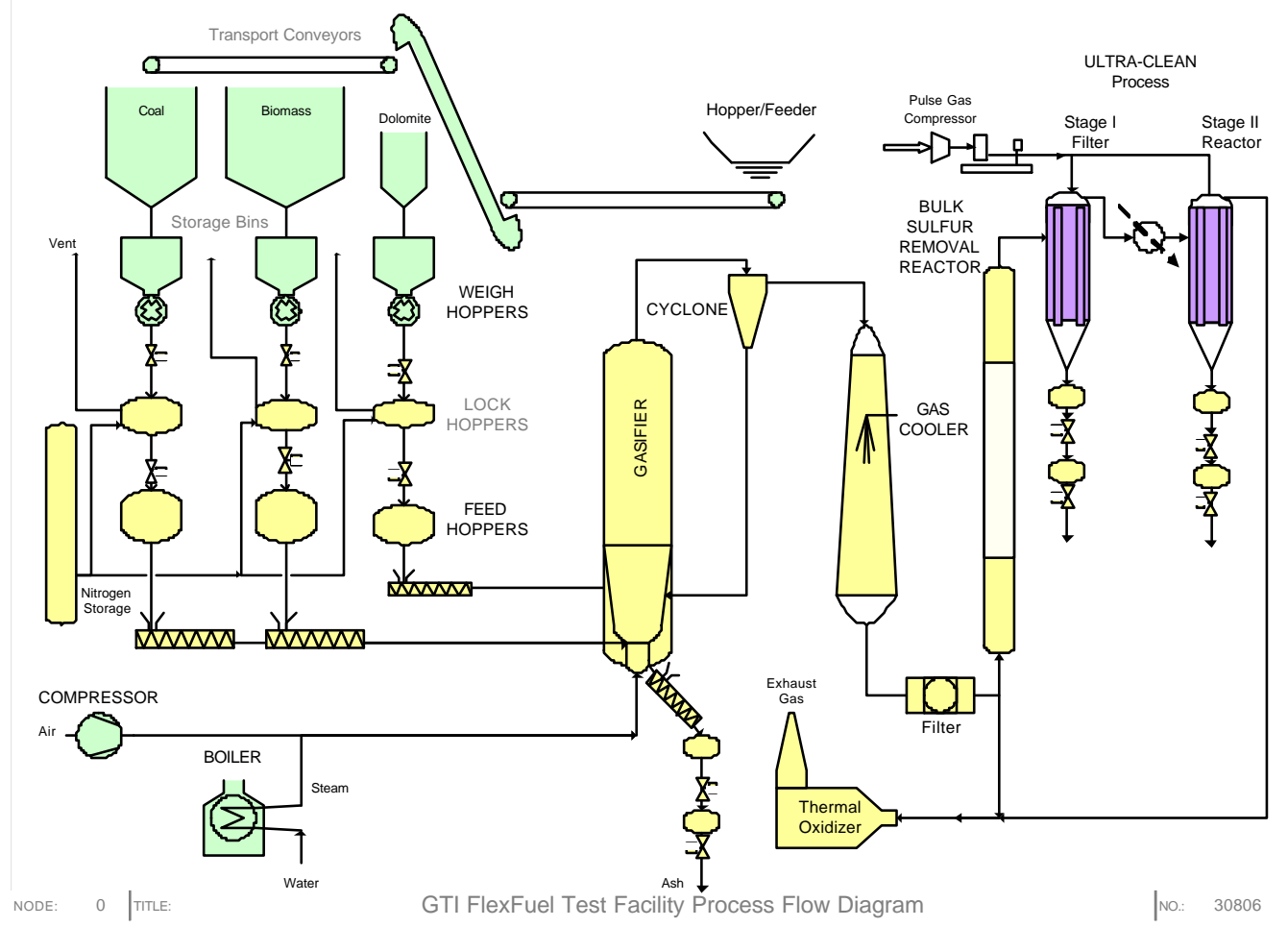

Figure 10. GTI's Solid Fuel Conversion Facility Process Flow Diagram 
Table 1. Chemical Analysis of Selected Sorbents

\begin{tabular}{|l|c|c|c|c|}
\hline \multirow{2}{*}{$\begin{array}{l}\text { Sorbent } \\
\text { Designation }\end{array}$} & \multicolumn{2}{|c|}{ Chemical Analysis, Wt.\% } & $\begin{array}{c}\text { Theoretical Sulfur Capacity* } \\
\text { (g S/100 g Sorbent) }\end{array}$ \\
\cline { 2 - 4 } & $\mathrm{Zn}$ & $\mathrm{Ti}$ & $\mathrm{Zr}$ & \\
\hline IGTSS-354 & 19.4 & 30.0 & 13.7 & 9.52 \\
\hline IGTSS-362C & 27.4 & 34.7 & & 13.44 \\
\hline UCI-4169 & 43.8 & 23.5 & & 21.48 \\
\hline
\end{tabular}

$*$ Based on $\mathrm{ZnO}+\mathrm{H}_{2} \mathrm{~S}=\mathrm{ZnS}+\mathrm{H}_{2} \mathrm{O}$

Table 2. Physical Characteristics of Selected Sorbents ${ }^{a}$

\begin{tabular}{lccccccc}
\hline $\begin{array}{l}\text { Sorbent } \\
\text { Designation }\end{array}$ & $\begin{array}{c}\text { Main } \\
\text { Reactive } \\
\text { Metal }\end{array}$ & $\begin{array}{c}\text { Particle } \\
(\mathrm{Hg}) \\
\text { Density } \\
\left(\rho_{\mathrm{b}}\right) \\
\left(\mathrm{g} / \mathrm{cm}^{3}\right)\end{array}$ & $\begin{array}{c}\text { Skeletal } \\
(\mathrm{He}) \\
\text { Density } \\
\left(\rho_{\mathrm{a}}\right) \\
\left(\mathrm{g} / \mathrm{cm}^{3}\right)\end{array}$ & $\begin{array}{c}\text { Hg Pore } \\
\text { Volume } \\
\left(\mathrm{cm}^{3} / \mathrm{g}\right)\end{array}$ & $\begin{array}{c}\text { Porosity } \\
(\%)\end{array}$ & $\begin{array}{c}\text { Surface } \\
\text { Area } \\
\left(\mathrm{m}^{2} / \mathrm{g}\right)\end{array}$ & $\begin{array}{c}\text { Median } \\
\text { Pore } \\
\text { Diameter } \\
(\AA)\end{array}$ \\
\hline IGTSS-354 & $\mathrm{Zn}$ & 2.53 & 4.12 & 0.153 & 38.6 & 56.92 & 110 \\
IGTSS-362C & $\mathrm{Zn}$ & 2.47 & 4.12 & 0.162 & 40.1 & 50.10 & 125 \\
UCI-4169 & $\mathrm{Zn}$ & 2.19 & 3.14 & 0.138 & 30.3 & 0.71 & 8200 \\
\hline
\end{tabular}

${ }^{\text {a }}$ Corrected for inter-particle void.

${ }^{b}$ Calculated based on corrected values as $\left(1-\rho_{b} / \rho_{a}\right) * 100$, or equivalently as $\rho_{b} *($ Hg Pore Volume $) * 100$ 